\title{
O relatório escrito em aulas de Cálculo Diferencial e Integral: a carta para a tia
}

The report written in classes of Differential and Integral Calculus: the letter to the aunt

\author{
Marcele Tavares Mendes* \\ André Luis Trevisan**
}

\section{Resumo}

Este texto discute a experiência de utilização de um relatório escrito enquanto instrumento de avaliação em aulas de Cálculo Diferencial e Integral. Para tal, lança mão de produções elaboradas por alunos matriculados em turmas sob responsabilidade dos autores, de cursos de Engenharia de uma universidade federal no Paraná entre os anos de 2014 e 2016. Buscou-se, por meio da proposição de uma carta destinada à "tia", gerar junto aos alunos um momento de aprendizagem a partir da reflexão do processo de aprendizagem já vivenciado. Do ponto de vista metodológico, a discussão realizada a partir da análise da produção escrita presente nos relatórios tem natureza qualitativa e se fundamenta em uma análise interpretativa. Evidenciamos, a partir da análise realizada, as potencialidades do instrumento tanto no valorizar dos processos vividos pelos alunos enquanto cursam a disciplina (em termos de suas angústias, frustações, aprendizagens, descobertas) quanto os produtos de sua aprendizagem (por meio dos diferentes registros de representação da qual lançam mão na elaboração de sua produção escrita).

Palavras-chave: Educação Matemática. Avaliação da Aprendizagem. Ensino de Cálculo. Relatório Escrito.

\section{Introdução}

Os processos de ensino e aprendizagem do Cálculo Diferencial e Integral (CDI) têm sido objeto de debate e pesquisa há algumas décadas, e propostas pedagógicas surgem no intuito de minimizar dificuldades dos alunos nesses processos. Pagani e Allevato (2014), por meio de um mapeamento de trabalhos em

\footnotetext{
* Doutora em Ensino de Ciências e Educação Matemática. Docente do Departamento de Matemática e do Programa de Mestrado Profissional em Ensino de Matemática - Universidade Tecnológica Federal do Paraná (UTFPR)/ campus Londrina. E-mail: marceletavares@utfpr.edu.br.

** Doutor em Ensino de Ciências e Educação Matemática. Docente do Departamento de Matemática e do Programa de Mestrado Profissional em Ensino de Matemática - Universidade Tecnológica Federal do Paraná (UTFPR)/ campus Londrina. E-mail: andrelt@utfpr.edu.br.
} 
dissertações e teses disponíveis em repositórios de Instituições de Ensino Superior Brasileira que abordam essa temática, verificaram que os altos índices de reprovação nos cursos iniciais de Cálculo constituem a principal motivação para realização dos trabalhos analisados, aspecto esse que corroboramos da experiência enquanto docentes da disciplina.

Grande parte dos trabalhos investigados por essas autoras são de natureza empírica, apresentando alguma experiência de ensino realizada com alunos e/ou professores. O objetivo comum destes trabalhos foi implementar e analisar, no ensino de CDI, metodologias e/ou estratégias de ensino investigando suas contribuições para a aprendizagem de assuntos como limites, derivadas e integrais. Se por um lado, tais trabalhos ${ }^{1}$ contribuem ao apresentar propostas de ensino, por outro, em pouco deixam transparecer elementos relativos ao processo de avaliação a elas subjacentes. Embora seja parte dos processos de ensino e aprendizagem, a avaliação (mesmo quando inerente a metodologias e/ou estratégias de ensino diferenciadas da prática tradicional - como a resolução de problemas, modelagem matemática o uso de tecnologias digitais de informação e comunicação) parece seguir moldes ditos "tradicionais".

No que tange a essa questão, Cunha (2013, p. 9-10), ao tratar da questão da "revisão da didática", impulsionada pelas "formas contemporâneas de se compreender o conhecimento, a aprendizagem e o ensino", destaca:

Parece que já temos uma base de experiências interessantes que estimulam o protagonismo do aluno para aprender. Entretanto, no momento da avaliação da aprendizagem, um desafio de impõe: como valorizar os processos vividos pelos estudantes na mesma importância dos produtos de sua aprendizagem? Como ser coerente com o discurso da diversidade e da produção criativa, convivendo com os tradicionais padrões pré-estipulados e generalizadores para avaliar os alunos? Como exercitar uma avaliação que assuma os princípios do ensino como produção do conhecimento e manter o rigor necessário à sua formação? (CUNHA, 2013, p. 9-10).

Motivados por essas questões, temos nos debruçado em investigar ações que, enquanto professores de CDI, mostrem-se factíveis frente às nossas

\footnotetext{
1 Inferência dos autores a partir da consulta os trabalhos citados por Pagani e Allevato (2014), a partir desse levantamento.
} 
condições reais de trabalho (RAMOS; FONSECA; TREVISAN, 2016), que se afastem de uma perspectiva de ensino e avaliação calcadas na transmissão do conhecimento e, portanto, mobilizem os alunos a assumirem o papel de protagonistas do seu processo de aprendizagem, mas, ao mesmo tempo, estejam alinhadas com a organização didático-pedagógica proposta pela instituição (estejam comprometidas com um currículo obrigatório, com o projeto políticopedagógico do curso, com a atribuição de uma nota ao fim de um período).

Este texto é oriundo de um projeto de pesquisa intitulado "Investigação de um ambiente educacional para o CDI em condições reais de ensino", submetido e aprovado no Edital Universal 14/2014 do CNPq. Seu objetivo geral é investigar os processos envolvidos na caracterização, na implementação e na avaliação de um ambiente de aprendizagem para a disciplina de CDI e suas consequências para a aprendizagem, considerando as condições reais às quais estamos sujeitos. Defendemos que tais ambientes sejam pautados em episódios de resolução de tarefas (adaptação da expressão shift problem lessons, proposta por Palha et al (2013) e Palha, Dekker e Gravemeijer (2015)), nas quais os alunos tenham um papel ativo trabalhando quando possível em grupos e em tarefas não precedidas de exemplos, que sejam desencadeadoras de discussões e que contribuam para elaborações conceituais. Um dos objetivos específicos do projeto em tela, aqui abordado, é investigar práticas avaliativas alinhadas com a organização didáticopedagógica proposta pela instituição.

Adotando uma perspectiva de avaliação enquanto processo a serviço da aprendizagem, trazemos o relatório escrito como um instrumento de avaliação que, aliado à análise da produção escrita, pode gerar informações para (re) orientar o trabalho do professor e orientar a aprendizagem dos alunos. De modo restrito, investigamos esse instrumento, com vistas a evidenciar suas potencialidades de ser utilizado como instrumento de avaliação da aprendizagem matemática, em especial, para o ensino de cálculo, no qual valoriza tanto os processos vividos pelos alunos na disciplina de CDI quanto os produtos de sua aprendizagem. 


\section{Avaliação da Aprendizagem e o Relatório Escrito}

Ancoramos nossa discussão em um processo de avaliação a serviço da aprendizagem, que acontece enquanto um elemento da prática pedagógica e exige dos envolvidos uma reflexão crítica sobre a prática, no sentido de captar seus avanços, suas resistências, suas dificuldades e possibilitar uma tomada de decisão sobre o que fazer para superar os obstáculos.

Nessa perspectiva, a avaliação se distancia de uma natureza classificatória que demarca e exclui pessoas, que acontece em momentos estanques e finais do processo de aprendizagem, para se aproximar de uma natureza didática, sendo exercida ao longo de toda a ação de formação, abarcando as funções de segurança, de assistência, de feedback, de diálogo. Segurança no sentido de consolidar a confiança do aluno nele mesmo; assistência por tornar-se um "ponto de apoio" para o progresso do aluno; feedback ao fornecer informações úteis sobre as etapas vencidas e as dificuldades encontradas; diálogo ao promover a existência de uma comunicação de qualidade entre professor e aluno (HADJI, 1994).

Essa avaliação requer estratégias e instrumentos planejados e coerentes ao que se busca avaliar. Autores que tratam do tema avaliação da aprendizagem defendem a necessidade de se diversificar os instrumentos de avaliação (HADJI, 1994; VAN DEN HEUVEL-PANHUIZEN, 1996; BARLOW, 2006). Pesquisas comprometidas com instrumentos de avaliação no contexto do Ensino Superior (em especial nas aulas de CDI) ainda carecem de investigação, pois apesar da variedade de meios para a avaliação escolar, a prova escrita tem sido utilizada como o principal, e, em muitos casos, o único instrumento, utilizado em momentos finais do ciclo de formação (provas bimestrais, provas de recuperação finais).

Suhr (2008) discute algumas sugestões de ações que podem contribuir para mudar essa prática avaliativa classificatória tão presente em todos níveis escolares e que pouco contribui para aprendizagem e para a formação de cidadãos éticos e conscientes: alterar a metodologia em sala de aula; diminuir a ênfase na avaliação pontual; reconhecer que o erro e a dúvida fazem parte do processo de aprendizagem; diversificar as formas de avaliação; elaborar provas com maior 
qualidade; avaliar com critérios claros, conhecidos pelos alunos; evitar os "trabalhinhos"; moralizar os trabalhos; comentar os resultados o mais rápido possível; avaliar não só os alunos.

Desde o ano de 2011, temos buscado investigar uma metodologia de ensino ${ }^{2}$ em nossas próprias aulas de CDI, em que aos alunos é dada a oportunidade de vivenciar um progressivo processo de matematização por meio de tarefas propostas em sala de aula, refletindo e compartilhando com os colegas as ideias e ferramentas utilizadas para lidas com as situações envolvidas. A avaliação é realizada por meio de diferentes instrumentos ${ }^{3}$ (prova escrita individual; prova escrita em grupo; prova escrita em fases; atividades avaliativas com recurso tecnológico - GeoGebra; apresentação da resolução de tarefas; defesa oral de resolução de tarefas; relatório escrito; portifólio).

Em particular, a elaboração de um relatório escrito, foco deste texto, requer do aluno (e/ou grupo de alunos) uma produção escrita na qual descreve, analisa e crítica uma dada situação (VALADARES, GRAÇA, 1999; VARANDAS, 2000; MENINO; SANTOS, 2004; SANTOS, PIRES, 2015). Além de se constituir como um instrumento de avaliação, configura-se enquanto oportunidade de aprendizagem, uma vez que o aluno tem que aprender a registar por escrito o seu pensamento, a organizar e articular as ideias e explicar procedimentos. O realizar um relatório pode desenvolver capacidades de raciocínio e comunicação, a persistência, a responsabilidade e contribuir para a construção de uma nova visão da atividade matemática.

2 Baseada nos pressupostos da Educação Matemática Realística (MENDES, 2014; TREVISAN; BURIASCO, 2015).

${ }^{3}$ O valor de cada atividade avaliativa é apresentado à turma no momento da discussão do Plano de Ensino no início do semestre letivo, em particular, o valor atribuído ao relatório escrito varia entre 15 a $30 \%$ da nota da disciplina, dependendo do número de atividades avaliativas desenvolvidas ao longo de cada semestre. 


\section{Aspectos metodológicos}

Nossa discussão baseia-se em um relatório escrito elaborado por alunos matriculados na disciplina de CDI, de cursos Engenharia de uma universidade federal no Paraná entre os anos de 2014 e 2016. Buscou-se por meio de uma produção escrita individual gerar um momento de aprendizagem a partir da reflexão do processo de aprendizagem já vivenciado. Os autores deste texto foram os professores responsáveis pelas turmas.

No Quadro 1, segue o enunciado da tarefa entregue aos alunos, adaptada da proposta apresentada por Santos (2005): produzir um relatório escrito (que utilizava como suporte uma carta destinada a um parente ou amigo), explicitando o que aprenderam ao finalizar um conteúdo, no intuito de explicitar tanto os processos por eles vivenciados quanto os produtos de sua aprendizagem, constituindo-se, portanto, como um instrumento de avaliação a serviço da aprendizagem.

Construa uma carta para sua "tia" explorando os conceitos estudados nas aulas de Cálculo nesses dois primeiros meses de aula. O objetivo é que você construa um veículo para dialogar com você mesmo e com sua "tia", que auxilie a organizar seu pensamento, ajudando-o a estudar melhor. Você escreverá livremente, aproveitando esse momento para pensar sobre seu processo de aprendizagem. Sua carta não será uma cópia do caderno, nem de livros. É uma atividade essencialmente pessoal, devendo contemplar também aspectos emocionais e afetivos ("gostei imensamente de estudar derivada", "pra que raios inventaram essa tal de integral?"). A carta deve ser recheada de exemplos e imagens, de preferência de sua própria criação, ilustrando os conceitos trabalhados em sala de aula, acompanhados de explicações. Também é fundamental incluir reflexões do tipo: o que entendi sobre este conceito? Por quê? O que não entendi? Por quê? Seu trabalho deve ter entre três e cinco laudas matemáticas.

Quadro 1: Enunciado da atividade avaliativa

Fonte: autores, adaptado de Santos (2005). 
Os assuntos para as aulas dessa disciplina buscam manter alguma similaridade com o seu desenvolvimento histórico e filosófico de suas principais ideias. Por meio de abordagens gráficas realiza-se uma exploração qualitativa, intuitiva e informal de ideias como taxa de variação e áreas sob curvas, que são gradativamente refinadas. Até o final do curso, o aluno tem a oportunidade de desenvolver os conceitos e operações de limites, derivadas e integrais de funções de uma variável real. No Quadro 2 está a organização dos conteúdos do cronograma da disciplina no momento em que a atividade fora proposta (já decorridos em média 2 meses de aula - 6 aulas semanais -60 aulas de um universo 111 aulas). Em todos os semestres em que atividade foi proposta, os alunos tiveram duas semanas para construir seus relatórios individuais.

Introdução histórica aos conceitos do Cálculo. O método da exaustão para um segmento parabólico.

$\mathrm{O}$ estudo das curvas. As ideias fundamentais da geometria cartesiana. Conceito de função. Operações com funções. Funções elementares.

Partições e funções escada. Definição e propriedades de integral para funções escada.

Integral definida para funções polinomiais. Aplicações da integral no cálculo de áreas e volumes.

Estudo do movimento e das tangentes. Noção intuitiva de derivada.

Noção intuitiva de continuidade.

Sistematização dos conceitos de derivada e integral.

Derivada de uma função e álgebra das derivadas.

Quadro 2: Enunciado da atividade avaliativa

Fonte: autores.

Do ponto de vista metodológico, essa discussão é um recorte de uma pesquisa de natureza qualitativa e de análise interpretativa. A análise da produção escrita foi o recurso utilizado para identificar e analisar a organização da carta para a tia; a descrição dos conceitos nela abordados, a coerência e clareza dos raciocínios desenvolvidos; a criatividade nos exemplos; os processos de aprendizagem vivenciados. 
Essa análise intenta evidenciar potencialidades do relatório escrito como instrumento de avaliação da aprendizagem matemática, em especial, para o ensino de cálculo. Conforme Santos (2014, p. 22),

A análise da produção escrita não tem como objetivo a atribuição de uma nota ou de um conceito. O objetivo é obter informações que possibilitem uma tomada de consciência do ocorrido nos processos de ensino e de aprendizagem e uma tomada de decisão de modo a auxiliar tanto professor quanto alunos a organizar e orientar suas ações (SANTOS, 2014, p. 22).

Segundo Smith, Hillen e Heffernan (2001), a análise da produção escrita dos alunos pode ser utilizada pelos professores na direção de obter um entendimento dos modos como os alunos estão pensando e representando a matemática. Esses autores assinalam que,

se os professores forem capazes de interpretar e entender os modos que os estudantes pensam e representam a matemática, eles podem utilizar estratégias de ensino sobre esses entendimentos, como também, ajudar os alunos a fazer conexões entre suas representações idiossincráticas e aquelas mais convencionais (SMITH; HILLEN; HEFFERNAN, 2001, p. 65).

\section{A carta para a tia - algumas potencialidades}

Essa tarefa, o aluno escrever a respeito de suas experiências matemáticas em aula de CDI, pode levá-lo a pensar criticamente sobre suas ideias, desenvolvendo a cognição matemática e desencadeando também processos metacognitivos (POWEL; BAIRRAL, 2006). A Figura 1 é um exemplo em que o aluno ao escrever a "carta para a tia" reconhece a necessidade de retomar um conceito trabalhado em sala de aula.

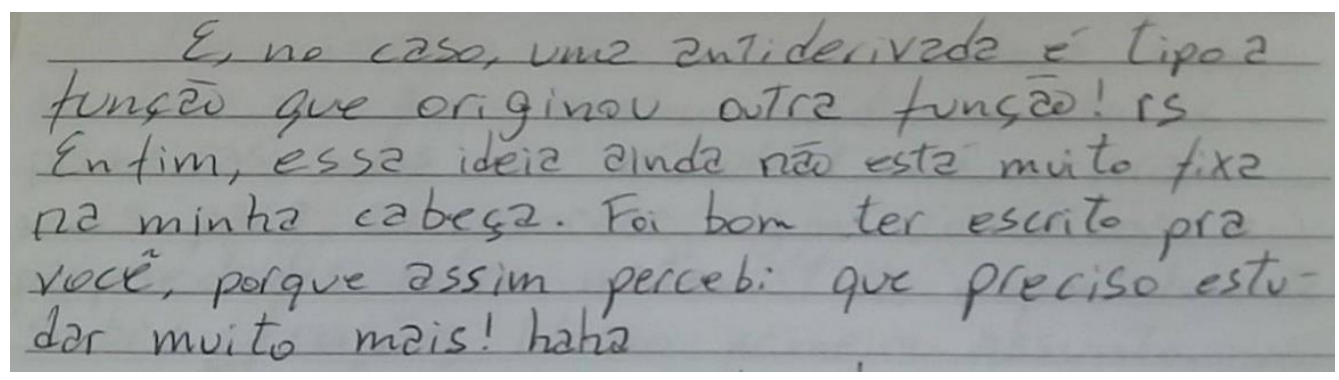

Figura 1: Indícios de uma metacognição.

Fonte: arquivo dos autores. 
No fragmento apresentado na Figura 2, fica evidenciada a escrita do relatório "carta para a tia" como uma oportunidade de o aluno buscar compreender o seu processo de aprendizagem, bem como a escrita "mais livre" como uma oportunidade do professor estabelecer um diálogo com o seu aluno, podendo recolher pistas de suas dificuldades e, com isso favorecer uma reorientação de seu processo de ensino, e com isso, favorecer que o aluno regule ${ }^{4}$ seu processo de aprendizagem.

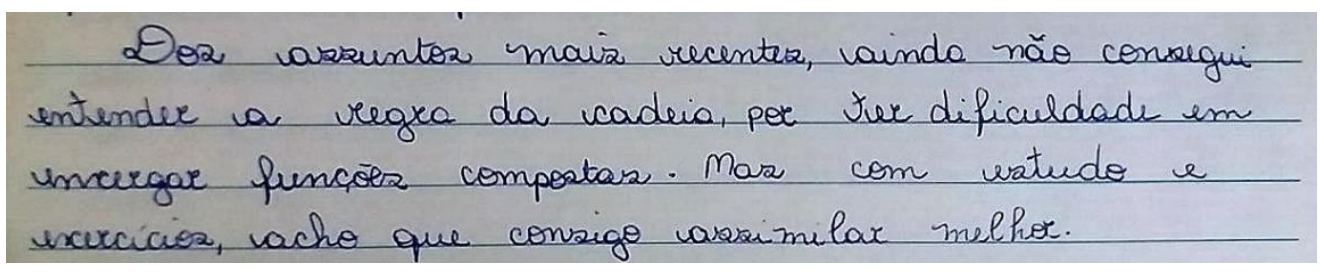

Figura 2: Metacognição e possibilidade de reorientação da prática de ensino. Fonte: arquivo dos autores.

Para esse aluno, o professor pode indicar um material de apoio, ou tarefas para serem discutidas com o monitor da disciplina e em horários de atendimentos individuais extraclasse, ou ainda, em caso de ser um comentário recorrente nos relatórios, o professor pode retomar o assunto em sala de aula com toda a turma.

Escrever uma carta, apesar de se ter um enunciado de uma tarefa a priori, pode favorecer uma liberdade de pensamento por meio da escrita, favorecendo que cada aluno expresse o seu modo de ver aquilo que se desenvolve em aulas, ela pode ser um meio de todo aluno ter "voz", de estabelecer uma comunicação de qualidade com o professor, aquela em que professor e aluno se entendem mutuamente.

É comum em salas de aula numerosas (40-50-60 alunos) de CDI apenas alguns alunos participarem ativamente das atividades (levantando questionamentos, respondendo as questões do professor), em trabalhos em grupos apenas alguns desenvolverem a atividade e os outros consentirem com a resolução apresentada, professores se comunicarem apenas por meio das provas escritas

\footnotetext{
${ }^{4}$ Regular o processo de aprendizagem está associado às ações realizadas pelo aluno sobre o seu processo de aprendizagem, com a intenção de fazê-lo progredir e/ou redirecioná-lo (MENDES, 2014).
} 
com seus alunos, ou seja, se o aluno não sabe realizar a prova escrita proposta pelo professor, a comunicação nem se inicia.

De modo particular, tomaremos dois trechos de diferentes cartas que dão indícios do significado do conceito de derivada que cada um dos autores das cartas construiu (Figuras 3 e Figura 4). Na Figura 3, o aluno estuda o comportamento de função a partir do sinal da função derivada, sem mencionar, pode ter compreendido a derivada de uma função $f$ em um ponto $x=a$ como o coeficiente angular da reta tangente a curva neste ponto (a taxa de variação instantânea em $x=a$ ) e a partir disso, ter realizado o estudo do gráfico da função. Apesar de não haver problemas em sua produção escrita, o professor (a tia que recebe a carta) pode solicitar que explique a relação que foi descrita em sua carta.

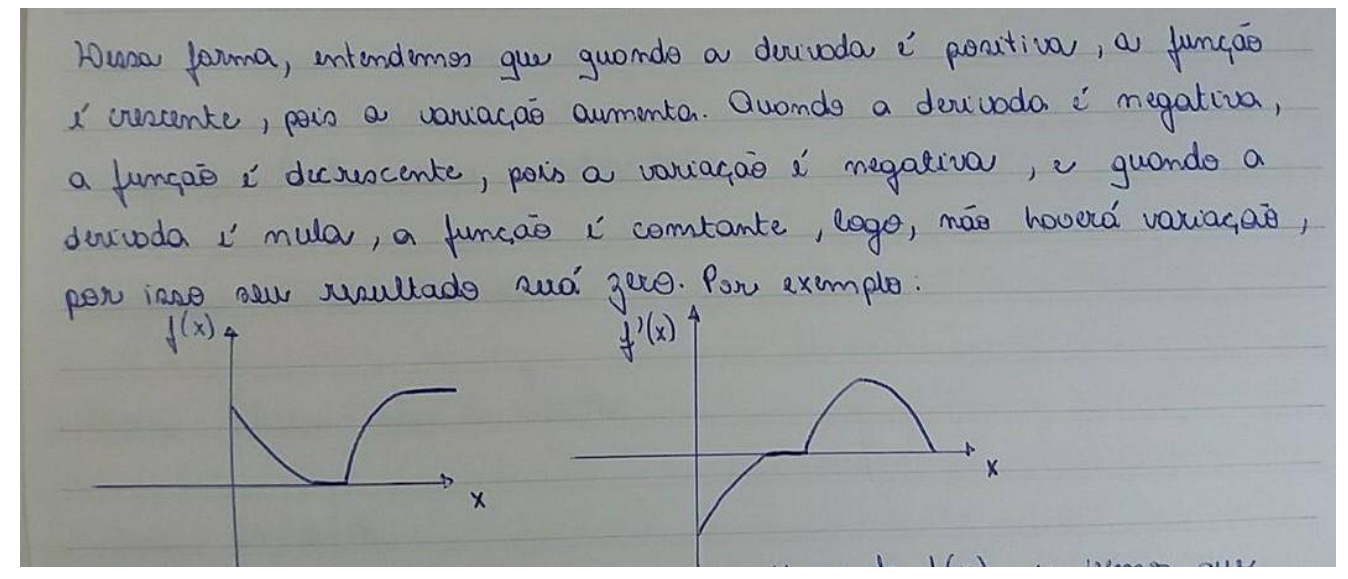

Figura 3: Significados para o conceito de derivada. Fonte: arquivo dos autores.

Mas se 0 aluno constrói um significado equivocado ${ }^{5}$ para a relação entre derivada e reta tangente conforme na Figura 4? Esse aluno, possivelmente terá dificuldades em compreender que a variação do crescimento de uma função está relacionada ao sinal da sua função derivada, do mesmo modo, o professor pode investigar essa dificuldade para orientar uma possível regulação da aprendizagem. Nessa direção, conforme Freitas e Fiorentini (2008), a escrita do aluno ajuda a

\footnotetext{
${ }^{5} \mathrm{~A}$ taxa de variação instantânea em $x_{0}$ não é representado pela inclinação da reta tangente em $x_{0}$, mas pelo valor de seu coeficiente angular.
} 
promover o diálogo, bem como o processo de produção e negociação de significados.

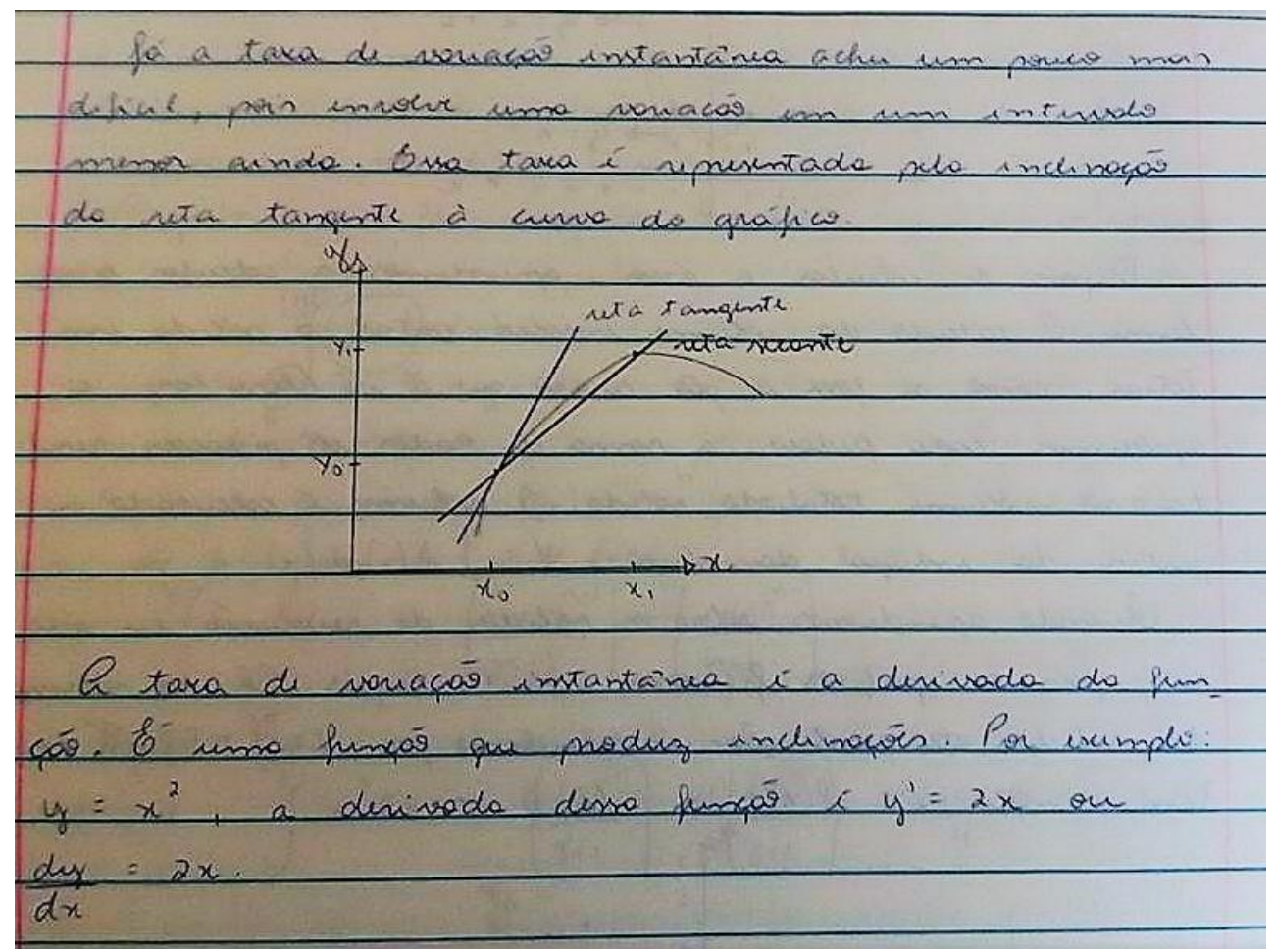

Figura 4: Significados para o conceito de derivada.

Fonte: arquivo dos autores.

Ao realizar a análise da produção escrita de um relatório escrito, o professor pode indagar-se a respeito de qual matemática "os seus estudantes estão aprendendo, que entendimentos estão tendo do que está sendo trabalhado em sala de aula, do que já sabem, que dificuldades encontram, e o que pode ser feito para auxiliá-los na superação destas" (BURIASCO, FERREIRA, CIANI, 2009, p. 78). No caso do aluno que desenvolveu a produção escrita da Figura 4, o professor precisa oportunizar que reconheça que a função derivada em $x=a$ não fornece diretamente a inclinação de uma reta tangente em $x=a$, mas o valor de seu coeficiente angular. $O$ como esse professor vai fazer para superar esse entendimento depende de suas escolhas pedagógicas, pode propor novas tarefas 
individuais ou em grupo, utilizar recursos tecnológicos, questionar o próprio relatório.

A elaboração de um relatório escrito pode promover no aluno um reconhecer-se construtor do próprio conhecimento, seguro de escolhas. Assim como é função da avaliação da aprendizagem oferecer essa segurança, também é da escola/universidade, desenvolver práticas que encorajem os alunos a se envolverem autonomamente. A Figura 5 dá indícios dessa segurança, ao expressar que, além de desenhar tal sólido de revolução, ele também é capaz de calcular seu volume, atividade que jamais pensou um dia fazer.

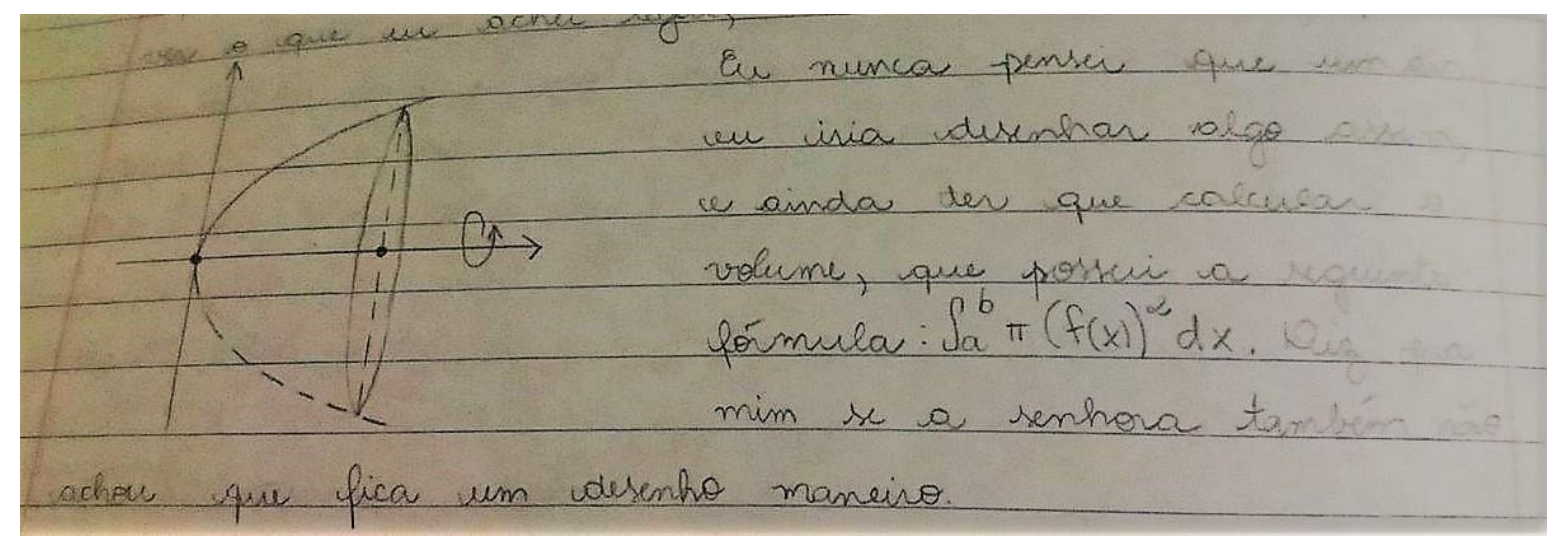

Figura 5: Segurança em desenvolver uma atividade.

Fonte: arquivo dos autores.

Solicitar que o aluno também traga elementos emocionais e afetivos em seu relatório pode ser um caminho de buscar o quão seguro e assistido ele se sente durante o processo. Na Figura 6 é apresentado um trecho em que o aluno desabafa o quão angustiante tem sido estar em sala de aula, que por mais que o professor busque criar um ambiente que favoreça a aprendizagem para todos, para ele não tem funcionado. Ao tomar contato com esse "desabafo", o professor pode agir, pode acompanhar de mais perto esse aluno, convidá-lo para seus atendimentos extraclasse e pedir ao monitor um atendimento mais individualizado. O professor teve a chance de ouvir seu aluno e agir ao durante o processo de aprendizagem. Muito possivelmente, esse aluno, sem essa atividade, não diria nada do que estava sentindo o semestre todo, dois meses de aulas já haviam se passado. 


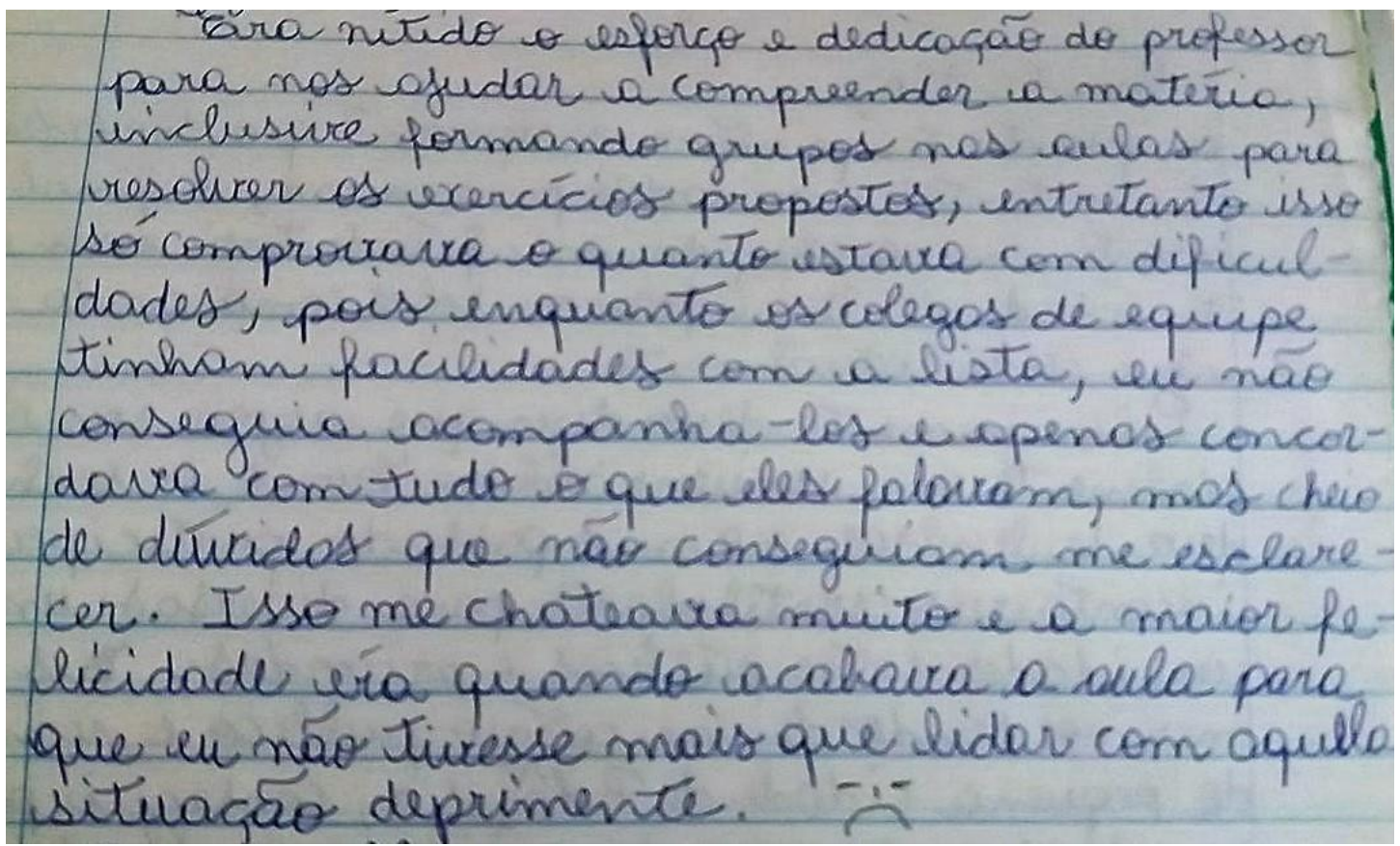

Figura 6: Angustia na sala de aula.

Fonte: arquivo dos autores.

Esse aluno reprovou ao final do semestre. Então de nada adiantou saber de sua angustia? De nada adiantou tentar um trabalho personalisado? Não, adiantou sim, esse aluno teve "voz" em seu processo de aprendizagem, trabalhou elementos da matemática da Educação Básica que poderão ajudá-lo no próximo semestre que cursar a disciplina. Ele não foi, simplesmente, "ignorado", como usualmente ocorre.

Outro aspecto que pode ser levantado: Cabe a universidade fazer um atendimento tão personalizado a cada aluno? Cabe ao professor buscar entender as angustias do aluno de seu processo de aprendizagemm? Defendemos que sim, cabe. Conforme Suhr (2008, p. 71)

Não é papel da educação superior apenas formar os profissionais que o mercado quer, mas também ajudar a construir pessoas conscientes da realidade, que possam, como cidadãos e como profissionais, contribuir para a transformação social rumo a uma sociedade mais justa (SUHR, 2008, p. 71).

A liberdade de escolhas instaurada ao realizar o relatório escrito - a carta para a tia - propiciou que os alunos valorizassem tanto os seus processos de aprendizagem vividos na disciplina de CDI quanto os produtos de sua 
aprendizagem, foi possível reconhecer diferentes registros de representação e caminhos para organização do conhecimento: esquemas que representavam o conteúdo a ser contado para a tia; definições como apresentadas em livros de CDI, narrativas sem uso de simbologia matemática, escrita estritamente por símbolos matematicos.

A Figura 7 e a Figura 8 são esquemas realizados por dois alunos, no qual é possível observar as transformações de funções canônicas. Por meio da produção escrita da Figura 7 o aluno apresenta para sua "tia" as transformações de diferentes funções elementares (quadráticas, com radicais, trigonométricas, polinomiais). Seu esquema não é prescritivo no sentido de dizer como são realizadas essas transformações a partir da função canônica, possivelmente esse aluno desenvolveu a habilidade de relacionar a representação gráfica e a lei de formação de uma função.

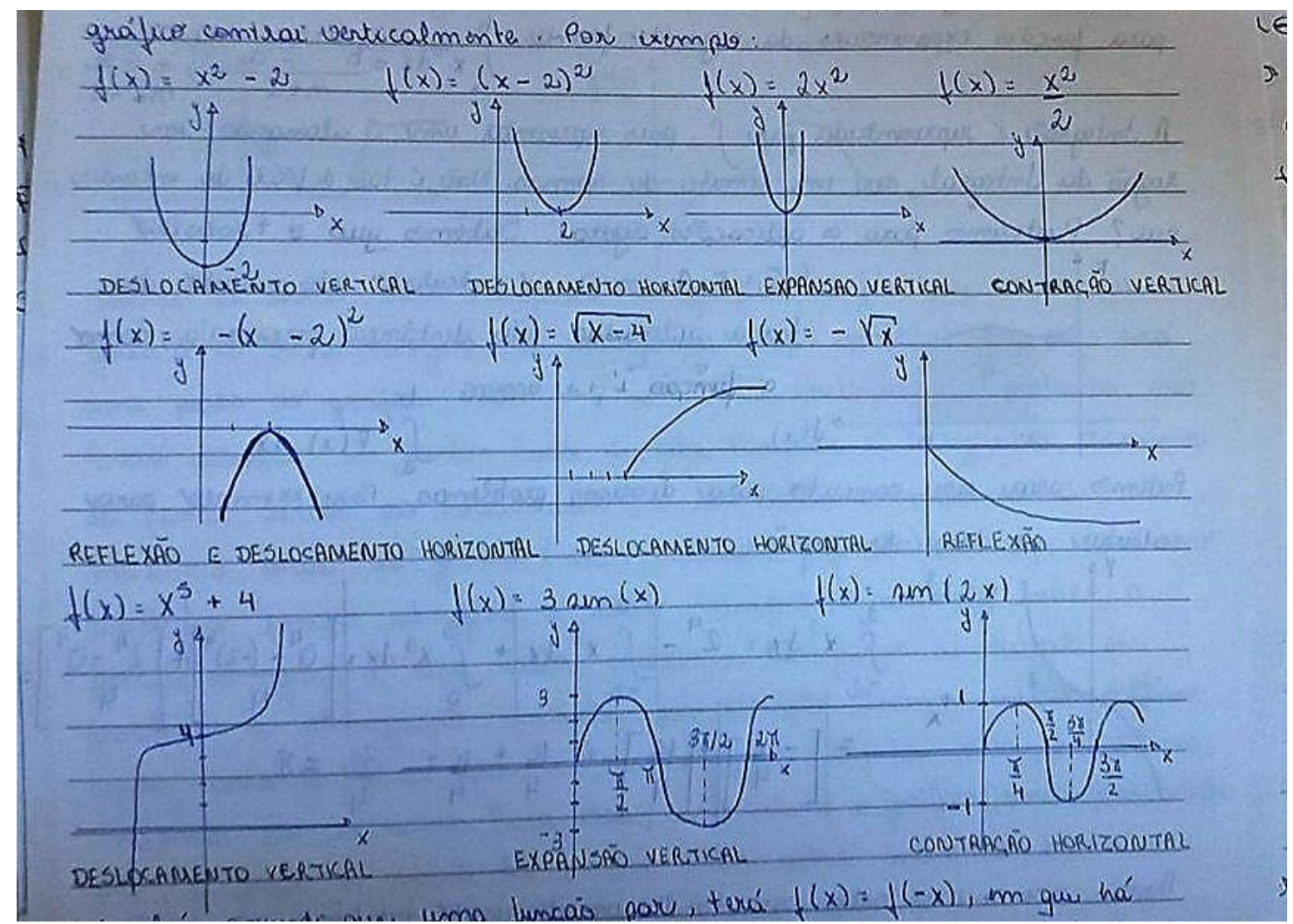

Figura 7: Produto de aprendizagem - esquema 1.

Fonte: arquivo dos autores. 
Já a Figura 8 é uma produção escrita em que um aluno também apresenta para sua "tia" transformações de uma função real de um modo genérico, apresenta um discurso que explica como proceder. Não há um juízo de valor entre as produções (Figura 7 e Figura 8), apenas evidencia como cada aluno tem a oportunidade de expressar como quiser aquilo que foi desenvolvido para o outro (no caso a "tia") enquanto um produto escrito.

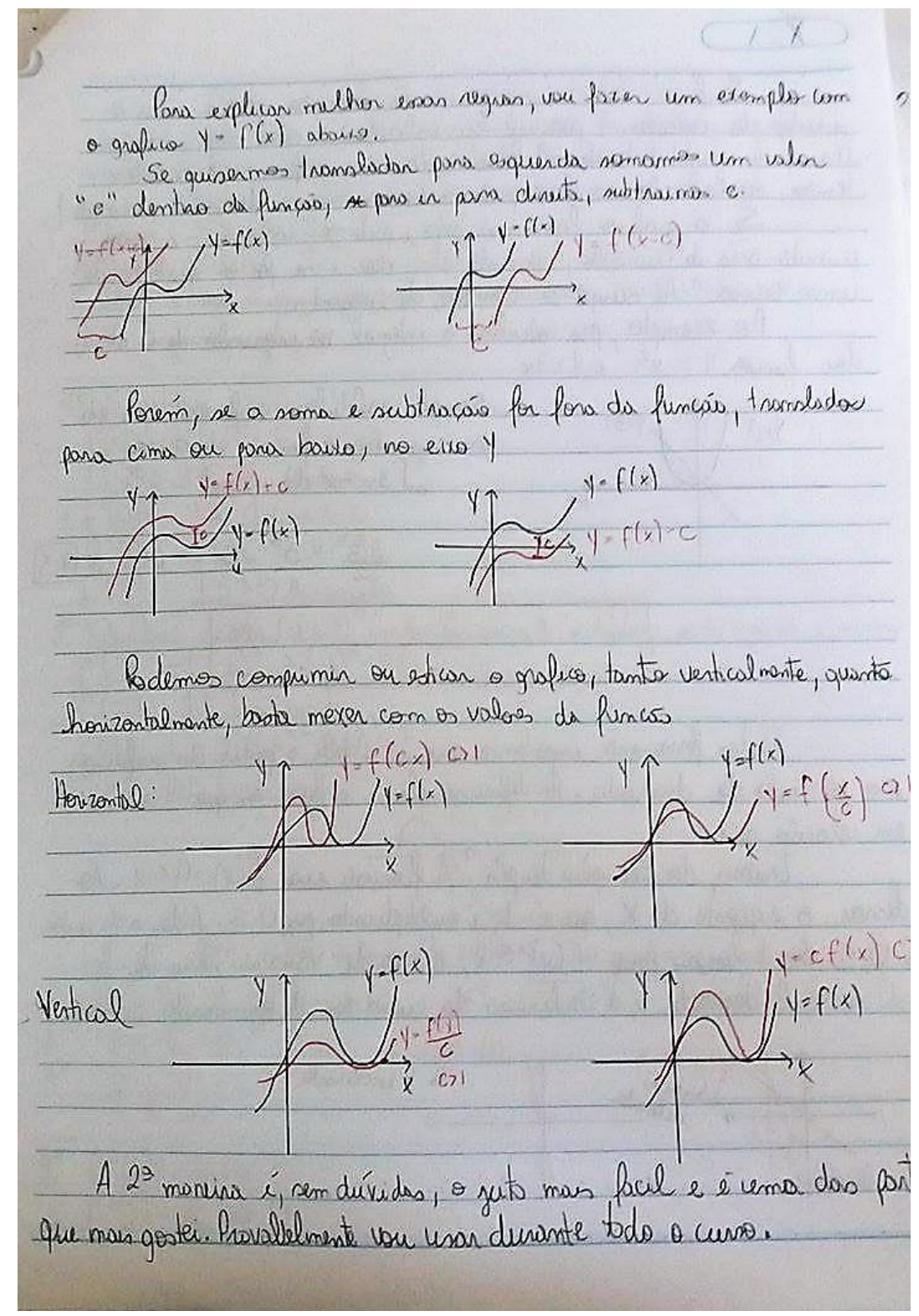

Figura 8: Produto de aprendizagem - esquema 1.

Fonte: arquivo dos autores. 
Ao se propor a elaboração de um relatório escrito não se busca identificar produções corretas ou incorretas, mas permitir que professor e aluno reflitam sobre o processo vivido, para a partir do que foi observado agirem para alcançar os objetivos traçados de ensino e de aprendizagem, respectivamente. Nessa reflexão, o professor analisa o desenvolvimento do aluno e o seu modo de lidar com as ferramentas matemáticas, e ao aluno é dada a oportunidade de revelar o que sabe, independentemente se é o que o professor estipulou que saiba.

E como avaliar o relatório? Conforme Santos e Pires (2015, p. 59), ao se corrigir os relatórios podem ser utilizadas escalas quantitativas e qualitativas, porém o importante é que o professor teça comentários para que os alunos tenham noção do que está bem esclarecido e dos aspectos que poderiam ser mais explorados". E que os critérios de elaboração e de correção sejam discutidos no momento em que atividade for proposta.

\section{Considerações}

Neste texto buscamos evidenciar algumas potencialidades do instrumento relatório em uma perspectiva de avaliação em que o interesse primeiro é servir a aprendizagem dos alunos. Conforme Esteban (2003, p.11), essa prática "vai sendo constituída como um processo que indaga os resultados apresentados, os trajetos percorridos, os percursos previstos, as relações estabelecidas entre as pessoas, saberes, informações, fatos, contextos".

A utilização do relatório escrito enquanto instrumento que serve a uma prática de avaliação da aprendizagem tem nos mostrado sua potencialidade ao promover uma comunicação de qualidade entre professor e aluno, sendo essa comunicação estabelecida por diferentes produções escritas. Mais importante que a forma dessa produção é o que os alunos dizem para si, para sua "tia", a respeito do que pensam e sentem quando aprendem matemática, o que constroem enquanto produto da aprendizagem, para que o professor tenha informações para gerir o processo que está a ser construído e vivido a partir do analisar essa escrita. 
Temos buscado desenvolver uma prática que vai de encontro ao raciocínio da adequação da educação, em que principalmente no Ensino Superior, "devido às demandas do mercado tende a empurrar as instituições de ensino a uma avaliação classificatória, assumindo o papel de pré-classificação daqueles que podem ou não concorrer às vagas de trabalho cada vez mais escassas" (SUHR, 2008, p. 70).

\section{Referências}

BURIASCO, Regina Luzia Corio de; FERREIRA, Pamela Emanueli Alves; CIANI, Andreia Buttner. Avaliação como prática de investigação (alguns apontamentos). BOLEMA Boletim de Educação Matemática, UNESP - Rio Claro, v. 22, n. 33, p. 69-96, 2009.

BARLOW, Michel. Avaliação escolar: mitos e realidades. Porto Alegre: Artmed, 2006.

CUNHA, Maria Isabel da. Prefácio I: iniciando a tessitura. In: AMBRÓSIO, M. O uso do portfólio no Ensino Superior. Petrópolis/RJ: Vozes, 2013.

ESTEBAN, Maria Teresa. A avaliação no cotidiano escolar. In: ESTEBAN, M. T. et al. Avaliação: uma prática em busca de novos sentidos. 5 ed. Rio de Janeiro: DP\&A, 2003.

FREITAS, Maria Teresa Menezes; FIORENTINI, Dario. Desafios e potencialidades da escrita na formação docente em matemática. Revista Brasileira de Educação, vol. 13, n.37, p.138-149, 2008

HADJI, Charles. A avaliação, regras do jogo: das intenções aos instrumentos. Tradução Júlia Lopes Ferreira e José Manuel Cláudio. 4. ed. Portugal: Porto, 1994.

MENDES, Marcele Tavares. Utilização da Prova em fases como recurso para aprendizagem em aulas de Cálculo. 2014. Tese (Doutorado em Ensino de Ciências e Educação Matemática) - Universidade Estadual de Londrina, Londrina, 2014.

MENINO, Hugo; SANTOS, Leonor. Instrumentos de avaliação das aprendizagens em matemática: o uso do relatório escrito, do teste em duas fases e do portefólio no $2^{\circ}$ ciclo do ensino básico. Anais... SIEM - Seminário de Investigação em Educação Matemática, 15. Lisboa: APM, 2004.

PAGANI, Érica Marlúcia Leite; ALLEVATO, Norma Suely Gomes. Ensino e aprendizagem de Cálculo Diferencial e Integral: um mapeamento de algumas teses e dissertações produzidas no Brasil. Vidya (Santa Maria. Online), v. 34, p. 61-74, 2014.

PALHA, Sonia Abrantes Garcêz; DEKKER, Rijkje: GRAVEMEIJER, Koeno; VAN HOUTWOLTERS, Bernadette. Developing shift problems to foster geometrical proof and understanding. The Journal of Mathematical Behavior. Springer, v. 32, p. $141-159$, 2013. 
PALHA, Sonia Abrantes Garcêz; DEKKER, Rijkje; GRAVEMEIJER, Koeno. The effect of shift-problem lessons in the Mathematics classroom. International Journal of Science and Mathematics Education, v. 13, 2015.

POWELL, Arthur; BAIRRAL, Marcelo. A escrita e o pensamento matemático: interações e potencialidades. Campinas: Papirus, 2006.

RAMOS, Nelvia Santana; FONSECA, Maycon Odailson dos Santos da; TREVISAN, André Luis. Ambiente de aprendizagem de Cálculo Diferencial e Integral pautado em episódios de resolução de tarefas In: V Simpósio Nacional de Ensino de Ciência e Tecnologia, 2016, Ponta Grossa. Anais... SINECT, 5. Ponta Grossa: Editora da UTFPR, v.1. p.1-11, 2016.

SANTOS, Sandra Augusta. Explorações da linguagem escrita nas aulas de Matemática.In: LOPES, Celi Aparecida Espasandin. Escritas e leituras na educação matemática. Belo Horizonte: Autêntica, 2005.

SANTOS, Edilaine Regina dos. Análise da produção escrita em matemática: de estratégia de avaliação a estratégia de ensino. 2014. Tese (Doutorado em Ensino de Ciências e Educação Matemática) - Universidade Estadual de Londrina, Londrina, 2014.

SANTOS, Edilaine Regina dos; PIRES, Magna Natalia Marin. O Relatório Como Instrumento Para Avaliação da Aprendizagem Matemática: Roteiro de ElaboraçãoCorreção e Uma Proposta de Utilização. Educação Matemática em Revista, p. 56-63, 2015.

SMITH, Margaret Schwan; HILLEN, Amy; HEFFERNAN, Cristina. Student-constructed representations: Vehicles for helping teachers understand students' mathematical thinking. In: BLUME, Glendon; HEID, Mary Kathleen; SMITH, Margaret Schwan. 2001 Yearbook of the Pennsylvania council of teachers of mathematics: The role of representation in the teaching and learning of mathematics, State College, PA: The Council of Teachers of mathematics, p. 65-69, 2001.

SUHR, Inge Renate Fröse. Processo avaliativo no ensino superior. Metodologia de Ensino na Educação Superior, v. 2. Curitiba: Ibpex, 2008.

TREVISAN, André Luis; BURIASCO, Regina Luzia Corio de. Educação Matemática Realística: uma abordagem para o ensino e a avaliação em Matemática. Revemat: Revista Eletrônica de Educação Matemática, v. 10, p. 167-184, 2015.

VALADARES, Jorge; GRAÇA, Margarida. Avaliando para melhorar a aprendizagem. Lisboa: Plátano Edições Técnicas, 1999.

VAN DEN HEUVEL-PANHUIZEN, Marja. Assessment and Realistic Mathematics Education. Utrecht: CD-ß Press/Freudenthal Institute, Utrecht University, 1996.

VARANDAS, José Manuel. Avaliação de investigações matemáticas. Uma experiência. Dissertação (Mestrado) Universidade de Lisboa, Lisboa: APM, 2000. 